\title{
Effects of smoking in pregnancy on neonatal lung function
}

Anthony D Milner, Michael J Marsh, Dorothea M Ingram, Grenville F Fox, Chakraphan Susiva

\begin{abstract}
Aims-To assess the effects of smoking during pregnancy on lung mechanics and lung volumes in the immediate neonatal period, before infants are exposed to passive smoking.

Methods-Lung function tests were carried out within 72 hours of delivery in infants born to 100 non-smoking and 189 smoking mothers. Lung growth was assessed by plethysmography and lung mechanics using the single breath occlusion technique and oesophageal balloon/ pneumotachography. Antenatal maternal serum cotinine values were obtained from 133 mothers.

Results-Smoking was associated with a significant reduction in birthweight (mean $256 \mathrm{~g}, 95 \% \mathrm{CI} 0.164$ to 0.392 ), and length (mean $1.26 \mathrm{~cm}, 95 \%$ CI 0.48 to 2.00 ). Lung volume was not reduced when related to weight. Smoking was associated with a highly significant reduction in static compliance $\left(\mathrm{C}_{\mathrm{rs})}\right.$. This effect remained significant after relating $C_{r s}$ to weight and lung volume. Regression analyses showed that the $\mathrm{C}_{\mathrm{rs}}$ association was limited to the boys. Smoking was associated with a small but significant reduction in respiratory system conductance $\left(G_{\mathrm{rs}}\right)$ (single breath occlusion technique) and total pulmonary conductance $\left(G_{p}\right)$. These associations were limited to girls.

Conclusions-Smoking in pregnancy reduces static compliance in boys and conductance in girls. There was no evidence that maternal smoking adversely affected fetal lung growth.

(Arch Dis Child Fetal Neonatal Ed 1999;80:F8-F14)
\end{abstract}

Keywords: maternal smoking; lung function; cotinine

Heavy maternal smoking (20+ daily) is associated with a reduction in birthweight and length of about $250 \mathrm{~g}$ and $1-2 \mathrm{~cm}$, respectively. ${ }^{12}$ Some studies also show that these effects are dose related. ${ }^{34}$ The mechanisms responsible are not fully understood, although nicotine is known to have adverse effects on the uteroplacental circulation. ${ }^{5}$

Maternal smoking is also associated with an excess of respiratory symptoms in the offspring, particularly in the first five years. ${ }^{6-8}$ Analysis of data from the British Birth Survey ${ }^{9}$ suggests that smoking only during pregnancy is as important as exposure to environmental tobacco smoke (ETS) after delivery, in the development of respiratory problems. There has been increasing evidence to support the hypothesis that smoking during pregnancy is an important risk factor for the development of respiratory symptoms in early life. ${ }^{10}$

Several studies have investigated the effects of maternal smoking on lung function in early infancy. Tager et $a l^{11}$ measured functional residual capacity (FRC) and also maximum expiratory flow at FRC ( $\left.\max \operatorname{mRC}_{\mathrm{FR}}\right)$, using the partial expiratory flow volume technique: expiratory flow pattern is measured during a forced expiration, caused by inflating a jacket surrounding the chest and abdomen. Although there was a tendency for those with lower lung function at 30-35 days of age to develop respiratory symptoms, only the reduction in $V_{\text {max }}$ FRC in girls exposed to antenatal smoking reached significance $(\mathrm{p}=0.03)$.

Hanrahan et $a l^{12}$ found a highly significant correlation between the Vmax $\operatorname{mRC}_{\text {FRC }}$ measured at 4.2 weeks and history of smoking, and a strong inverse correlation between antenatal maternal urinary cotinine concentrations and $\operatorname{Vmax}_{\mathrm{FRC}}$. In contrast, Martinez et $a l^{13}$ were unable to detect a significant effect of maternal smoking on either the total respiratory resistance or on the $\mathrm{T}_{\mathrm{PTEF}} / \mathrm{T}_{\mathrm{E}}$ (the time taken for expiratory flow to peak expressed as a proportion of the total expiratory time) on infants aged 2-6 months.

One problem with all these studies is that the infants had already been exposed to ETS before the lung function tests had been carried out. Two studies avoided this problem by measuring the $\mathrm{T}_{\mathrm{PTEF}} / \mathrm{T}_{\mathrm{E}}$ within the first three days. ${ }^{14}{ }^{15}$ Both found that it was significantly shorter in babies born to mothers who smoked than in the controls, but the associations were weak $(p=0.04$ and 0.022 , respectively) despite sample sizes in excess of 500. In the second study ${ }^{15}$ respiratory system compliance was significantly lower in the girls who had been exposed to smoke than in female controls $(\mathrm{p}=$ 0.05), but not the boys.

This study therefore aimed to measure lung volumes in the immediate neonatal period to determine whether smoking during pregnancy was associated with a reduction in FRC as this might provide a mechanism whereby babies exposed to smoking tended to have subnormal lung mechanics; to measure lung mechanics using two independent techniques before any exposure to ETS had occurred; and to explore further the relation between $\mathrm{T}_{\mathrm{PTEF}} / \mathrm{T}_{\mathrm{E}}$ and maternal smoking.

\section{Methods}

Mothers were recruited either immediately before or within 24 hours of delivery. The aim was to recruit 100 mothers who had never 
smoked (non-smokers), 100 mothers who smoked 1-10 cigarettes a day (mild smokers), and 100 mothers who smoked in excess of 10 cigarettes a day (moderate smokers).The hospital records were first inspected to identify smoking habits. The mothers were then approached by one of the investigators (MM) and their current smoking habit ascertained at personal interview. The mothers were asked to provide a figure which best represented their cigarette intake.

Mothers who did not have a regular abode were excluded as we wished to follow up the infants for the next 12 months. No attempt was made to match for maternal age, social class, parity or intention to breastfeed. Infants born by normal vaginal delivery were studied after the age of 24 hours, those born by caesarean section after the age of 48 hours, to allow for time for pulmonary adaptation to occur. ${ }^{16}$ Only full term infants and those who were free from any apparent cardiorespiratory conditions were included. Social class was catagorised on a scale of 1 to 6 using tables from the Standard Occupational Classification (Office for $\mathrm{Na}$ tional Statistics). Those whose partners were unemployed, or who were unsupported single mothers were classified as 6 .

The birthweight was recorded using standard electronic scales, and length using an infant stadiometer and occipito-frontal circumference (OFC) with a tape measure. Measurements of chest wall circumference were also obtained at the level of the nipples using the tape measure. These latter three measurements were obtained at the time the lung function tests were carried out.

No sedation was used for lung function tests. All infants were studied 1 to 2 hours after a feed, while asleep. A $3 \mathrm{~cm}$ soft latex balloon mounted on a 6 French gauge catheter was passed at least $16 \mathrm{~cm}$ through the mouth so that it lay in the stomach.

The open end of the catheter was attached to the oesophageal pressure port of the PEDS system (Medical Associated Services Inc., Hatfield, PA19440) While displaying pressure on the PEDS screen the catheter was withdrawn until negative pressures were generated by the infant's inspiratory rate. The balloon was then withdrawn by a further $2 \mathrm{~cm}$ to ensure that it lay in the lower third of the oesophagus. The function of the oesophageal balloon was assessed by comparing mouth pressure with oesophageal pressure during periods of face mask occlusion lasting for 4 to 5 breaths. A ratio of 0.9 to 1.1 was considered acceptable. Tidal exchange was measured using a Fleisch OO pneumotachograph with a soft round rubber flanged face mask.

The dead space of the system was reduced to near zero by extracting 2 litres/minute from the face mask using a vacuum pump attached to a 21 French gauge butterfly needle inserted into the face mask at a point where it could not come into contact with the infant. ${ }^{17}$ This created a bias flow across the pneumotachograph and through the face mask. The face mask was lowered on to the infant's face to achieve a seal. Measurements were taken once the infant had settled, was asleep, and was breathing quietly with no limb or body movements, no evidence of swallowing and no observable eye movements. Recording was continued until 100 breaths were accepted by the PEDS system. The PEDS system has a sampling frequency of $75 \mathrm{H}_{\mathrm{z}}$ per channel and uses the least mean square analysis technique to determine pulmonary mechanics based on the Rohrer theoretical lung model. ${ }^{18}$ The multiple correlation coefficient for the least mean square analysis must be at least 0.98 for both the inspiratory and expiratory phases of the breath for acceptance by the system.

From tidal flow, integrated tidal volume, and oesophageal pressure data, the PEDS system computed dynamic compliance $\left(\mathrm{C}_{\mathrm{D}}\right)$ and total pulmonary resistance $\left(R_{p}\right)$. The $R_{p}$ was expressed as its reciprocal conductance $\left(G_{p}\right)$ to provide more normally distributed data. Breaths were only accepted if the inspiratory and expiratory volumes were within $0.5 \mathrm{ml}$ and the inspiratory/expiratory volumes and pressure swings were both within $10 \%$.

The flow trace obtained during the $\mathrm{C}_{\mathrm{D}}$ and $\mathrm{R}_{\mathrm{p}}$ measurement was used to obtain $\mathrm{T}_{\mathrm{PTEF}} / \mathrm{T}_{\mathrm{E}}$ values. The first period of regular breathing was selected and 10 sequential breaths were analysed using a cursor system to calculate the time to peak expiratory flow expressed as a fraction of total expiratory time.

The PEDS system was also used to calculate the static respiratory system compliance (Crs), the time constant, and the respiratory resistance (Rrs) by measuring face mask pressure during occlusions lasting $0.2-0.4$ seconds, and the expiratory flow volume curve after release of the occlusion. Breaths were only accepted if at least $50 \%$ of the expiratory flow volume curve was linear. This portion of the curve was extrapolated to zero flow to correct for dynamic increase in FRC. The technique was repeated until 20 satisfactory occlusions were collected. As with the $R_{P}$ data, the Rrs results were expressed as conductance $\left(\mathrm{G}_{\mathrm{Rrs}}\right)$.

The thoracic gas volume (TGV) was measured using a 48 litre total body plethysmograph. ${ }^{19}$ A bias flow of air (2 litres/min) passed through a tube which ran from the base of the plethysmograph via a shutter system and into the face mask. The bias flow gas then left the face mask by a second tube leading to the wall of the plethysmograph, again, via the shutter system.

The infants were nursed in the right lateral position and a soft latex coated face mask advanced to produce an airtight seal around the infant's face and nose. Thoracic gas volume was calculated by closing the shutter to occlude all the ports to the shutter at the end inspiratory port. Tidal volume, mouth pressure, and plethysmograph chamber pressure were recorded on ultraviolet sensitive paper.

The pressure transducer was calibrated against a water column and the plethysmograph chamber pressure against a $2 \mathrm{ml}$ syringe which was used to inject and withdraw volumes of air from the chamber at about the infant's respiratory rate to reduce error from the 
adiabatic effect. The shutter was held occluded for 4 to 5 breaths.

The manoeuvre was repeated at least five times and the results calculated manually using standard techniques. ${ }^{20}$ The TGV was then corrected for dead space $(25 \mathrm{ml})$ and for the inspiratory volume at which the occlusion occurred.

The frequency responses of the systems were assessed by connecting each pressure transducer and all conducting tubing to a spherical glass bottle containing an inflated balloon. The balloon was then punctured by a needle pushed through the cork in the bottle. The oesophageal and mouth pressure transducers of the PEDS system had a $63 \%$ rise time of 2 milliseconds and the associated pneumotachograph and tubing 4 milliseconds. The $63 \%$ rise time of the total body plethysmograph mouth pressure transducer was 6 milliseconds and plethysmograph chamber pressure transducer and associated pneumotachograph differential pressure transducer were both 8 milliseconds. Thus all systems had a frequency response, which up to $10 \mathrm{~Hz}$, showed no significant damping.

Serum cotinine concentrations were measured using blood sample obtained when the mothers first attended the antenatal clinic and subsequently stored at $-70^{\circ} \mathrm{C}$.

The sample size of 300 was selected as this was considered to be the largest that could be recruited and studied with the time and facilities available. Based on data obtained on a previous cohort of healthy newborn babies studied to investigate the effects of second trimester amniocentesis on neonatal lung function, ${ }^{21}$ we calculated that 100 infants in each group would give us an $80 \%$ probability of detecting a $4 \mathrm{ml}$ (12\%) difference in $\mathrm{TGV} / \mathrm{kg}$, a $1.3 \mathrm{ml}(21 \%)$ difference in $\mathrm{C}_{\mathrm{D}}$ and $0.125(24 \%)$ difference in $G_{p}$ at the $5 \%$ level. Neither the $C_{D}$ or the $G_{P}$ results were corrected for weight or lung volume for these trial size calculations.

Group differences between the infants born to maternal non-smokers and smokers were assessed by contingency table methods for categorical outcomes ( $\chi^{2}$ analysis). For continuous outcomes, the unpaired two tailed Studen'st $t$ test was used. The Kruskal-Wallis non-parametric ANOVA test was selected for analysis of the cotinine results.

Regression analysis was also used to assess the effects of the reported daily consumption of cigarettes on neonatal lung function. Where a range of cigarette consumption was given by the mothers, the mean value was used-for example, 15-when the reported number of

\section{Key messages}

- Smoking during pregnancy has an adverse effect on birthweight, length, head and chest circumference

- The lungs of boys but not girls infants born to smoking mothers have reduced compliance

- The lungs of girls but not boys born to smoking mothers have increased airways resistance, possibly due to the growth suppression effect

- Pulmonary hypoplasia is not responsible for the increase in respiratory symptoms associated with antenatal smoking

cigarettes smoked was 10 to 20 . The data obtained on the boys and girls were analysed separately to see if there was a gender effect.

Finally, stepwise regression analyses were carried out to assess the possible confounding effects of maternal age, social class, gestational age, Apgar score at birth, and age at the time of study on associations between the gender dependent lung function results and cigarette consumption.

The project was passed by the ethics committee of St Thomas's Hospital. Fully informed oral and written consent was obtained from at least one parent. The parents were encouraged to be present during the lung function measurements.

\section{Results}

Over 400 mothers were invited to take part in the study. Of these, around 100 decided not to. No data were collected on these mothers. Of the smokers, 11 had given up smoking during pregnancy; these babies were withdrawn from the analyses.

As our initial analyses showed that there were no significant differences in any of the outcome variables between the babies born to the 91 mild and the 98 heavier smokers, all the data from these 189 mothers and their babies were pooled.

The non-smoking mothers were on average 2.78 years older than the smokers (table 1). There were also highly significant social class differences, with $61 \%$ of the non-smokers coming from social classes 1 and 2, compared with $27.8 \%$ of mild smokers and only $12.5 \%$ of moderate smokers $(p=0.001)$. Only $8 \%$ of the non-smokers were in social classes 5 and 6 compared with 23.3 and $31.3 \%$ of the mild

Table 1 Demographic and somatic data (mean values (+/-1 standard deviations) are given where appropriate)

\begin{tabular}{|c|c|c|c|c|}
\hline & Non-smoking group & Smoking group & Difference between groups & $95 \%$ CI of difference \\
\hline Number & 100 & 189 & & \\
\hline Male/female & $54 / 45$ & $95 / 94$ & & \\
\hline Delivery (LSCS \%) & 24 & 19 & & \\
\hline Maternal age (years) & $30.3(5.1)$ & $27.5(6.0)^{\star \star \star}$ & 2.78 & 1.40 to 4.16 \\
\hline Gestation (weeks) & $39.5(1.5)$ & $39.1(1.46)^{\star}$ & 0.416 & 0.071 to 0.76 \\
\hline Age at test (h) & $61.6(24.0)$ & $56.8(24.0)$ & 4.79 & -1.111 to 10.7 \\
\hline Birth weight (kg) & $3.49(0.41)$ & $3.20(0.49)^{\star \star \star}$ & 0.278 & 0.164 to 0.392 \\
\hline Length $(\mathrm{cm})$ & $52.5(3.1)$ & $51.3(3.1)^{\star \star}$ & 1.24 & 0.48 to 2.00 \\
\hline Occipitofrontal circumference $(\mathrm{cm})$ & $34.8(1.5)$ & $34.0(1.4)^{\star \star \star}$ & 0.752 & 0.385 to 1.12 \\
\hline Chest circumference $(\mathrm{cm})$ & $33.0(1.5)$ & $32.2(1.94)^{\star \star \star}$ & 0.828 & 0.382 to 1.26 \\
\hline
\end{tabular}

${ }^{\star}$ p 0.01 to $0.05 ;{ }^{\star \star}$ p 0.001 to $0.01 ;{ }^{\star \star \star} \mathrm{p}<0.001$. 


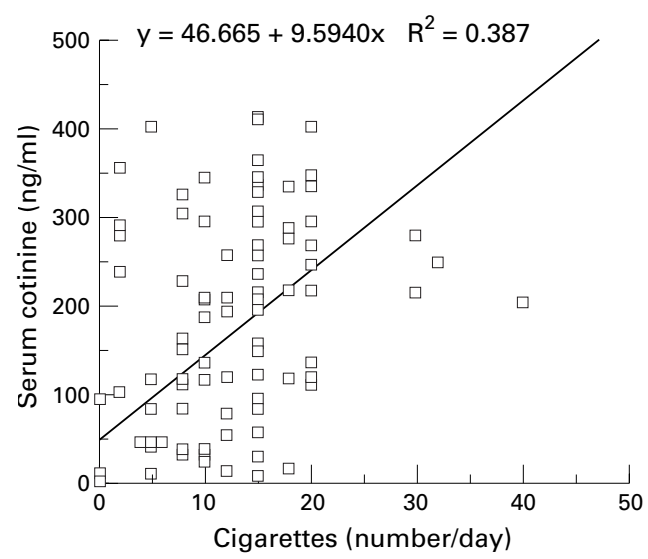

Figure 1 Correlation between serum cotinine concentrations and reported cigarette consumption.

and moderate smokers. Two hundred and eighty three were Caucasian, 30 of the mothers were of Indian subcontinental extraction, five were Mongolian and one was Afro-Caribbean. There was no statistical relation between ethnic origin and smoking habit.

A family history of asthma or eczema in a first degree relative was sought from 92 of the non-smokers and 137 of the smoking mothers, respectively. The incidence reported was 10.9 , and $7.3 \%$, respectively. These differences were not significant. The mean gestational age was longer in the non-smokers $(p<0.05)$, but this only amounted to around 3 days.

There was an excess of boys in the nonsmoking group (table 1), but these differences were not significant ( $\chi^{2}$ test). The number of infants born by lower section caesarean section (LSCS) was lower in the babies born to smoking mothers but this was not significant.

Cotinine results were analysed on serum samples collected between 10 and 20 weeks of gestation on 135 of the mothers and subsequently stored at $-70^{\circ} \mathrm{C}$. Only one of the 47 mothers claiming not to smoke had cotinine values above $25 \mathrm{ng} / \mathrm{ml}$. There was, however, a relatively poor correlation between the number of cigarettes claimed to have been smoked and the serum cotinine values (fig 1 ).

The mean values for birthweight, length, OFC and chest wall circumference were all significantly greater in the infants born to nonsmokers than in those born to smokers (table 1).

Placental weights were very similar, $615 \mathrm{~g}$ in the babies born to non-smoking mothers (number 92) and 631 in the smoking group (number 164). The mean difference was $15 \mathrm{~g}$ (95\% CI -48.8 to 16.6 ), $\mathrm{p}=0.34$.

Results were obtained on 99 of the nonsmoker and 181 of smoker babies. The results failed to distinguish between maternal smokers and non-smokers $(p=0.50)$ and had very wide variabilities with mean values (+/-SD), respectively, of 0.499 (0.121) and $0.509(0.119)$ and a mean difference of -0.01 (95\% confidence intervals -0.039 to 0.0195$)$. No significant association emerged after subdivision into gender subgroups.

Satisfactory TGV measurements were obtained in 81 of the control and 183 of the smoke exposed infants. The control group had a significantly higher TGV, mean 101.3 (93.9) $\mathrm{ml}$ with SDs of 18.7 and 17.5, respectively, and a mean difference of $7.4 \mathrm{ml}$ (95\% CI 2.7 to 12 $\mathrm{ml}) ; \mathrm{p}=0.002$. These differences disappeared when the TGVs were related to body weights, mean (SD) values 29.5 (5.3) and 29.8 (6.4), respectively, mean difference -0.27 (95\% CI -1.88 to 1.32 ).

Static compliance measurements were obtained on all 289 of the infants using the single breath occlusion technique There was a $25.6 \%$ reduction in $\mathrm{C}_{\mathrm{rs}}$ in those born to smokers compared with the non-smoking controls ( $\mathrm{p}<$ 0.0001) (table 2). The differences remained significant after the $\mathrm{C}_{\mathrm{rs}}$ had been related to body weight and TGV (specific static compliance) (table 2).

Dynamic compliance measurements were obtained in 87 of the control and 169 of the smoking group. In 32 babies (13 controls and 19 smoking exposed) we were unable to obtain satisfactory oesophageal traces with mouth pressure to oesophageal pressure ratios lying outside the 0.9-1.1 acceptance range during periods of occlusion. The $C_{D}$ was slightly higher in the control than the smoking group $(\mathrm{p}$ $=0.013$ ), but these small differences were no longer apparent when the $C_{D}$ values were related to body weight $(\mathrm{p}=0.50)$ (table 2$)$.

The Grs results ( all 289 babies) showed a small but significant mean reduction in the babies born to smoking mothers $(\mathrm{p}=0.004$ ) (table 3). A significant relation was no longer apparent when the Grs results were related to lung volume (specific respiratory system conductance, $\left.S . G_{\mathrm{rs}}\right)(\mathrm{p}=0.48)($ table 3$)$.

The mean $G_{p}$ and $S G_{p}$ results showed non-significant trends towards lower results in the smoke exposed groups $(\mathrm{p}=0.22$ and 0.311 , respectively) (table 3 ).

The linear regression analyses revealed that there was a highly significant inverse relation between the number of cigarettes consumed and the $\mathrm{C}_{\mathrm{rs}}$ for boys $(\mathrm{p}=0.0001)$ but not for girls $(p=0.11)($ table 4$)$. This pattern persisted when the $C_{r s}$ was related to body weight and to lung volume (static $\mathrm{C}_{\mathrm{rs}}$ ). No significant inverse relation was seen between $C_{D}$ and cigarette consumption in either of the gender subgroups

Table 2 Results of compliance measurements (mean values (+/-1 standard deviations) are given where appropriate)

\begin{tabular}{lllll}
\hline & $\begin{array}{l}\text { Non-smoking } \\
\text { group }\end{array}$ & Smoking group & $\begin{array}{l}\text { Difference between } \\
\text { groups }\end{array}$ & $\begin{array}{l}\text { 95\% CI of } \\
\text { difference }\end{array}$ \\
\hline Static compliance $\left(\mathrm{ml} / \mathrm{cm} \mathrm{H}_{2} \mathrm{O}\right)$ & $4.77(1.64)$ & $3.55(1.18)^{\star \star \star}$ & 1.22 & 0.89 to 1.55 \\
Static compliance $/$ weight $\left(\mathrm{ml} / \mathrm{cm} \mathrm{H}_{2} \mathrm{O} / \mathrm{kg}\right)$ & $1.37(0.44)$ & $1.13(0.38)^{\star \star \star}$ & 0.24 & 0.15 to 0.34 \\
Static compliance $/ \mathrm{TGV}\left(\mathrm{ml}^{2} / \mathrm{cm} \mathrm{H}_{2} \mathrm{O}\right)$ & $0.045(0.015)$ & $0.038(0.012)^{\star \star \star}$ & 0.007 & 0.0036 to 0.010 \\
Dynamic compliance $\left(\mathrm{ml} / \mathrm{cm} \mathrm{H}_{2} \mathrm{O}\right)$ & $5.83(1.32)$ & $5.42(1.50)^{\star}$ & 0.41 & 0.04 to 0.79 \\
Dynamic compliance $/$ weight $\left(\mathrm{ml} / \mathrm{cm} \mathrm{H} \mathrm{H}_{2} \mathrm{O} / \mathrm{kg}\right)$ & $1.70(0.44)$ & $1.74(0.54)$ & -0.04 & -0.18 to 0.09 \\
\hline
\end{tabular}

${ }^{\star}$ p 0.01 to $0.05 ;{ }^{\star \star}$ p 0.001 to $0.01 ;{ }^{\star \star \star}$ p $<0.001$. 
Table 3 Results of conductance measurements (mean values (+/-1 standard deviations) are given where appropriate)

\begin{tabular}{|c|c|c|c|c|c|c|}
\hline & & Non-smoking group & Smoking group & $\begin{array}{l}\text { Difference between } \\
\text { groups }\end{array}$ & \multicolumn{2}{|c|}{$95 \%$ CI of difference } \\
\hline $\begin{array}{l}\text { Respiratory conductance }(1 / \mathrm{s} / \mathrm{cm} \\
\text { Specific respiratory conductance }( \\
\text { Pulmonary conductance }(1 / \mathrm{s} / \mathrm{cm} H \\
\text { Specific pulmonary conductance }\end{array}$ & $\begin{array}{l}\left.\mathrm{H}_{2} \mathrm{O}\right) \\
\left(\mathrm{cm} \mathrm{H}_{2} \mathrm{O}\right) \\
\mathrm{O}) \\
\left./ \mathrm{cm} \mathrm{H}_{2} \mathrm{O}\right)\end{array}$ & $\begin{array}{l}0.017(0.004) \\
0.181(0.053) \\
0.037(0.027) \\
0.399(0.293)\end{array}$ & $\begin{array}{l}0.016(0.004)^{\star \star} \\
0.177(0.044) \\
0.032(0.029) \\
0.351(0.335)\end{array}$ & $\begin{array}{l}0.001 \\
0.003 \\
0.005 \\
0.04\end{array}$ & $\begin{array}{l}0.00 \\
-0 . \\
-0 . \\
-0 .\end{array}$ & $\begin{array}{l}8 \text { to } 0.000182 \\
\text { to } 0.0154 \\
\text { to } 0.012 \\
5 \text { to } 0.086\end{array}$ \\
\hline \multicolumn{7}{|c|}{${ }^{\star} \mathrm{p} 0.01$ to $0.05 ;{ }^{\star \star} \mathrm{p} 0.001$ to $0.01 ;^{\star \star \star} \mathrm{p}<0.001$} \\
\hline \multicolumn{7}{|l|}{ Table 4} \\
\hline & Group & Number & Slope coefficient & $S E$ & $r 2$ & $p$ Value \\
\hline \multirow[t]{2}{*}{ Static compliance } & Boys & 148 & -0.094 & 0.013 & 0.159 & 0.0001 \\
\hline & Girls & 140 & -0.023 & 0.014 & 0.019 & 0.11 \\
\hline \multirow[t]{2}{*}{ Static compliance/weight } & Boys & 148 & -0.015 & 0.004 & 0.094 & 0.0001 \\
\hline & Girls & 140 & -0.002 & 0.004 & 0.001 & 0.653 \\
\hline \multirow[t]{2}{*}{ Specific static compliance } & Boys & 132 & -0.0004 & 0.0001 & 0.098 & 0.0003 \\
\hline & Girls & 138 & -0.00002 & 0.0004 & 0.0002 & 0.884 \\
\hline \multirow[t]{2}{*}{ Dynamic compliance } & Boys & 130 & 0.001 & 0.015 & 0.00001 & 0.927 \\
\hline & Girls & 126 & -0.016 & 0.015 & 0.009 & 0.299 \\
\hline \multirow[t]{2}{*}{ Respiratory conductance } & Boys & 148 & -0.000027 & 0.000003 & 0.004 & 0.421 \\
\hline & Girls & 140 & -0.00010 & 0.000034 & 0.061 & 0.0033 \\
\hline \multirow[t]{2}{*}{ Specific respiratory conductance } & Boys & 131 & -0.00036 & 0.00045 & 0.005 & 0.429 \\
\hline & Girls & 132 & -0.00037 & 0.0005 & 0.004 & 0.45 \\
\hline \multirow[t]{2}{*}{ Pulmonary conductance } & Boys & 130 & -0.000063 & 0.0003 & 0.0003 & 0.86 \\
\hline & Girls & 125 & -0.00041 & 0.0005 & 0.034 & 0.041 \\
\hline \multirow[t]{2}{*}{ Specific pulmonary conductance } & Boys & 113 & -0.0018 & 0.004 & 0.002 & 0.68 \\
\hline & Girls & 117 & -0.0028 & 0.002 & 0.051 & 0.195 \\
\hline
\end{tabular}

(table 5). A significant inverse relation was found between the $G_{r s}$ and the $G_{p}$ in the girl subgroup ( $p=0.0033$ and 0.041$)$ but not in the boy subgroup ( $\mathrm{p}=0.421$ and 0.86 ) (table 4). The significant inverse relations with cigarette numbers were no longer apparent when the $G_{r s}$ and the $G_{p}$ were related to lung volume $\left(S . G_{r s} p=0.45\right.$ and $\left.S . G_{p} p=0.195\right)$ in the girl subgroup (table 4).

We explored the possible confounding effects of maternal age, social class, Apgar score at birth, gestation and age at the time of test on the sex dependent regression relations between cigarette consumption and lung function results by using multiple linear regression analyses. A significant relation found on linear regression was not displaced by any of these potential confounders on any subsequent analysis.

\section{Discussion}

The main aim of this study was to investigate the effects of smoking on lung function at birth, allowing sufficient time for lung fluid resorption to occur, but studying the babies before any exposure to ETS. An obvious major problem in such a study is to ensure that smoking habits are correctly recorded. The cotinine results indicated that most mothers who claimed not to smoke were non-smokers. On the other hand, there was also a relatively poor correlation between serum cotinine concentrations and reported smoking habit, suggesting that some mothers were under recording their intake. In contrast, five mothers claimed to smoke between 5 and 18 cigarettes per day and yet had serum cotinine values of below 25 $\mathrm{ng} / \mathrm{ml}$. However, as we only had cotinine results on 133 of the total cohort, no adjustment was made to correct for these findings.

This action is supported by a recent publication by Margolis and colleagues, ${ }^{22}$ who found a poor correlation between urinary cotinine and reported cigarette consumption and concluded that these measurements will not necessarily improve the validity of studies into the effect of passive smoking.

Our data on the effects of smoking during pregnancy on fetal growth are very similar to those published before, ${ }^{1-4}$ with a reduction in mean birthweight of $278 \mathrm{~g}$ in the smoking group, compared with the controls. Smoking during pregnancy was also associated with a highly significant reduction in length and head and chest wall circumference.

Although we were unable to obtained information on all placental weights, there was no evidence to suggest any relation between smoking and placental size, despite a relatively close correlation between birthweight and placental size $\left(r^{2}=0.48\right)$.

The lung function tests were selected on the grounds that they would provide information on lung size and lung mechanics, and had been used extensively in the newborn period before. We included measurements of $\mathrm{T}_{\mathrm{PTEF}} / \mathrm{T}_{\mathrm{E}}$ as these data could be calculated without submitting the babies to further investigation and low values have been shown to correlate with indices of airways obstruction in infants and young children. $^{23} 24$

The results of the expiratory flow analyses failed to show any adverse effects of maternal smoking. The main problem we encountered was that the $\mathrm{T}_{\mathrm{PTEF}} / \mathrm{T}_{\mathrm{E}}$ results ranged from 0.18 to 0.83 with a mean around 0.50 , indicating that the infants had very variable breathing patterns, a problem which has been reported in infants studied in the immediate neonatal period. ${ }^{25}$ These findings, however, conflict with the data published by Stick et $a l,{ }^{14}$ who found a significant but small association between smoking more than 10 cigarettes a day during pregnancy and lower $\mathrm{T}_{\mathrm{PTEF}} / \mathrm{T}_{\mathrm{E}}$ in the first few days of life $(p<0.05)$. The main differences from this study were that inductance plethysmography was used, avoiding the need for a face mask which may have 
influenced breathing patterns, and data were only collected when chest and abdominal movements were in phase, leading to more reproducible results.

The recently published study by Carlsen et $a l^{15}$ used similar techniques to those of this project and found a reduction in the ratio on smoking exposure $(p=0.04)$, but only after over 500 infants had been recruited.

Although the uncorrected TGV results suggested that maternal smoking might be associated with low lung volumes, this relation disappeared when TGV was related to body weight or length, indicating that lung volume had been appropriate for somatic size. This makes it most unlikely that smoking during pregnancy has its adverse effect by producing pulmonary hypoplasia as has been suggested before. ${ }^{26} 27$

Of greater interest was the highly significant reduction in Crs in the smoking group which remained significant after correction for body weight and lung volume. The regression analyses indicated that this effect was limited to the boys. There was also a small, non-significant reduction in $\mathrm{C}_{\mathrm{D}}$, although this may have purely been a result of the effects of smoking on body size as the differences disappeared once the $C_{D}$ had been corrected for body weight or lung volume.

In contrast, Carlsen et al, ${ }^{15}$ using the same technique, found a significant reduction in $\mathrm{C}_{r}$ corrected for body weight in the girls rather than the boys, but the relation was much weaker $(p=0.05)$ than our findings in boys ( $p$ $<0.0001$ ) despite their relatively large sample size. Brown et a ${ }^{28}$ has also reported a reduction in $\mathrm{C}_{\mathrm{rs}}$ in 10 infants born to smoking mothers but did not examine the effect of gender and the changes did not reach significance.

The multiple regression analyses failed to show any confounding effect from gestational age or age at the time of study on the relation between cigarette consumption and the $\mathrm{C}_{\mathrm{rs}}, \mathrm{C}_{\mathrm{rs}} /$ weight or specific $\mathrm{C}_{\mathrm{rs}}$ in the boy subgroup, which might have explained the findings. Maternal smoking might have had an adverse effect on surfactant production in the boys in the immediate neonatal period. This is unlikely in view of the TGV measurements and in conflict with previous studies which have shown that maternal smoking reduces the incidence of the respiratory distress syndrome in preterm babies. ${ }^{29}$

An alternative explanation is that maternal smoking delays the clearance of lung fluid in boys. No babies developed transient tachypnoea, a condition caused by persistence of lung fluid, but the presence of respiratory symptoms was an exclusion criteria. Serial measurements of $\mathrm{C}_{\mathrm{rs}}$ in the neonatal period would resolve the extent to which these findings are transitory. The failure of the $C_{D}$ results to mirror the $C_{r s}$ findings may be technological as this measurement is frequency dependent, tending to overestimate lung stiffness when breathing rates exceed 50 per minute nor does it take account of dynamic increase in the FRC which often occurs in neonates. ${ }^{30}$ In this study the correlation between $\mathrm{C}_{\mathrm{rs}}$ and the $\mathrm{C}_{\mathrm{D}}$ results was poor $(\mathrm{r}$ $\left.0.255, \mathrm{r}^{2} 0.065\right)$.
The effect of maternal smoking on $G_{r s}$ was relatively small, with regression analyses showing a significant negative effect in the girls $(\mathrm{p}=$ $0.003)$ but not the boys $(p=0.33)$. The $G_{p}$ findings were more marked but again limited to the girls $(p=0.04, p=0.86)$. These results are similar to those of Brown et $a l,{ }^{28}$ who found a small reduction in $R_{\mathrm{rs}}$ in babies born to non-smokers, in a smaller cohort, and those of Tager et $a l,{ }^{11}$ who could only show a significant inverse relation between $\operatorname{Vmax}_{\mathrm{FRC}}$ and smoking in girls and not boys. All these studies suggested that airway development in female fetuses is more susceptible to the adverse effects of maternal smoking than that of the male.

The conductance results could have reflected the effects of smoking on somatic growth in view of the failure to find a significant relation between numbers of cigarettes consumed and the specific conductance values. We consider this unlikely as it does not explain the gender differences because the somatic effects occurred to a greater extent in the boys (322 g, 95\% CI 0.161-0.403, $224 \mathrm{~g}$, $95 \%$ CI $0.0625-0.386$ ), whereas the conductance associations are limited to the girls. An alternative explanation is that the increased lung recoil in the boys tends to hold the airways open which would have the effect of increasing conductance measurements.

In conclusion, this study has found adverse effects of maternal smoking on somatic size at birth which are very similar to data in previous publications. There was a reduction in $\mathrm{C}_{\mathrm{rs}}$ in the boys born to smoking mothers but no significant effect in the girls. In contrast, both the $G_{r s}$ and $G_{p}$ were significantly reduced in the girls but not the boys. We were unable to find any evidence that maternal smoking had a specific adverse effect on lung volume. These findings support the hypothesis that antenatal smoking damages the developing lung, although the mechanism responsible is not known

We greatly appreciate financial support from the Tobacco Products Research Trust, the Special Trustees of St Thomas's Hospital, and the Children Nationwide Medical Research Fund. We also thank Professor J Banatvala, who very kindly allowed us to assay the blood samples obtained during pregnancy for cotinine.

The Tobacco Products Research Trust was set up by the government as an independent scientific committee but funded by money from the tobacco industry. Projects were submitted for consideration by the committee after independent peer review. The committee required annual and final reports, and that copies of papers should be sent to the Trust at least 4 weeks before submission for publication. The production of the research protocol, data collection, analysis and production of the manuscript were totally independent of the Trust.

1 Lam SK, To WK, Duthie SJ, Ma HK. The effect of smoking during pregnancy on the incidence of lowbirth weight 1992;32:125-8.

2 Wen SW, Goldenberg RL, Cutter GR, et al. Smoking, maternal age, fetal growth, and gestational age at delivery. Am F Obstet Gynecol 1990;162:53-8.

3 Bardy AH, Seppala T, Lillisunde P, Kataja JM, Koskela P, Pikkarainen J, Hiilesmaa VK. Objectively measured tobacco exposure during pregnancy: neonatal effects and relation to maternal smoking. $\mathrm{Br} \mathcal{F}$ Obstet Gynaecol 1993;100:721-6.

4 Hebel JR, Fox NL, Sexton M. Dose-response of birth weight to various measures of maternal smoking during pregnancy. f Clin Epidemiol 1988;41:483-9.

5 Teasdal F, Ghislaine JJ. Morphological changes in the placentas of smoking mothers: a histomorphometric study. Biol Neonate 1989;55:251-9. 
6 Colley JRT, Holland WW, Corkhill RT. Influence of passive smoking and parental phlegm on pneumonia an bronchitis in early childhood. Lancet 1974;ii:1031-4.

7 Fielding JE, Phenow KH. Health effects of involuntary smoking. N Engl f Med 1988;319: 1452-60.

8 Weitzman M, Gortmacher SL, Walker DK, Sobol A. Maternal smoking and childhood asthma. Pediatrics 1990;85:50511.

9 Taylor B, Wadsworth J. Maternal smoking during pregnacy an lower respiratory tract illness in early life. Arch Dis Child 1987;62:766-91.

10 Campbell MJ, Lewry J, Wailoo M. Further evidence for the effect of passive smoking on neonates. Postgrad Med $f$ 1988;64:663-5

11 Tager IB, Hanrahan JP, Toseson TD. Lung function, preand post-natal smoke exposure and wheezing in the first year of life. Am Rev Respir Dis 1993;147:811-17.

12 Hanrahan JP, Tager IB, Segal MR. The effect of maternal smoking during pregnancy on early infant lung function. Am Rev Respir Dis 1992;145:1129-35.

13 Martinez FD, Morgan WJ, Wright AL, Holberg CJ, Taussig LM. Diminished lung function as a predisposing factor for wheezing respiratory illness in infants. $N \mathrm{Engl} \mathrm{f} \mathrm{Med}$ 1988;319:1112-17.

14 Carlsen L, Jaakkola LLK, Nafstad P, Carlsen K-H. In utero exposure to cigarette smoking influences lung function at birth. Eur Respir F 1997;10:1774-9.

15 Stick SM, Burton PR, Gurrin L, Sly PD, LeSouef PN. Effects of maternal smoking during pregnancy and a family history of asthma on respiratory function in newborn infants. Lancet 1996;348:1060-4

16 Milner AD, Saunders RA, Hopkin IE. Effects of delivery by Caesarean section on lung mechanics and lung volumes in the human neonate. Arch Dis Child 1978;53:545-9.

17 Marsh MJ, Ingram D, Milner AD. The effect of dead space on measurement of breathing patterns and pulmonary mechanics in the newborn. Pediatr Pulmonol 1993;16:31622 .

18 Bhutani VK, Sivieri EM, Abbasi S, Shaffer TH. Evaluation of neonatal pulmonary mechanics and energetics: A two
factor least mean square analysis. Pediatr Pulmonol 1988;4:150-8.
19 Le Souef PN, England SJ, Bryan AC. Passive respiratory mechanics in newborns and children. Am Rev Respir Dis 1984;129:552-62.

20 Beardsmore CS, Stocks J, Silverman M. Problems in the measurement of thoracic gas volume in infancy. $\mathcal{F} \mathrm{Appl}$ Physiol 1982;52:995-9.

21 Milner AD, Hoskyns EW, Hopkin IE. The effects of mid trimester amniocentesis on lung function in the neonatal period. Eur F Pediatr 1992;151:458-60.

22 Margolis PA, Keyes L, Greenberg RA, Bauman KE, LaVange LM. Urinary cotinine and parental history (questionnaire) as indicators of passive smoking and predictors of lower respiratory illness in infants. Pediatr Pulmonol 1997;23:417-23.

23 Martinez F, Morgan W, Wright A, et al. Diminished lung function as a predisposing factor for wheezing respiratory

24 Cutrera R, Filtchev S, Merolla R, William G, Haluszka J, Ronchetti R. Analysis of expiratory pattern for monitoring bronchial obstruction in school-age children. Pediatr Pulmonol 1991;10:6-10.

25 Stocks J, Dezateux CA, Jackson EA, AH-Fong Hoo, Costeloe KL, Wade AM. Analysis of tidal breathing parameters in infancy: How variable is T $T_{\mathrm{T}} \mathrm{T}$. Am 7 Respir Crit Care Med 1994;150:1347-54.

26 Collins MH, Moessinger AC, Kleinerman J F, et al. Lung hypoplasia associated with maternal smoking: a morphometric analysis. Pediatr Res 1985;219:408-12.

27 Escolar MA, Martinez MN, Rodriguez FL, Gonzalo C, Escolar MA, Roche PA. Emphysema as a result of involuntary exposure to tobacco smoke : morphometric study of the rat. Exp Lung Res 1995;21;255-73.

28 Brown RW, Hanrahan JP, Castile RG, Tager IB. Effect of maternal smoking during pregnancy on passive respiratory

29 White E, Shy KK, Daling JR, Guthrie RD. Maternal smoking and infant respiratory distress syndrome. Obstet Gynecol 1986;67:365-70.

30 England SA. Current techniques for assessing pulmonary function in the newborn and infant. Pediatr Pulmonol $1988 ; 4: 48-53$. 